\title{
Assessment of total fatness and fatty tissue distribution in young active and physically inactive women
}

\author{
Anna Kopiczko, Aleksandra Bogucka
}

Department of Anthropology and Health Promotion, Department of Biomedical Sciences, Faculty of Physical Education, Józef Piłsudski Academy of Physical Education, Warsaw, Poland

\section{Summary}

Study aim: The aim of the study was to evaluate the total fat and fat distribution in young active and physically inactive women. Material and methods: The study group consisted of a total of 300 students from Warsaw aged 20 to 25 years. The weekly physical activity level expressed in metabolic equivalent task was assessed using the International Physical Activity Questionnaire. The distribution of adipose tissue was assessed on the basis of anthropometric measurements by somatometry. The waist and hip circumference, body mass and height were measured. Body mass index and waist to hip ratio were calculated. General fat was evaluated by bioelectric impedance.

Results: Physically active students had significantly lower $(\mathrm{p}<0.001)$ body mass, waist and hip circumference, lower body fat content and lower BMI and WHR compared to inactive students. Weight loss and the gynoidal type of adipose tissue distribution were more frequent among physically active subjects. In inactive women the androidal-abdominal type of distribution dominated. A healthy somatic profile characterized by BMI in the normal range, gynoid type of adipose tissue distribution and normal or slightly lower body fat was significantly more frequent in physically active subjects (36\% vs. 15\%).

Conclusions: Lack of physical activity was associated with larger waist and hip circumference, higher BMI and unfavorable adipose tissue distribution (androidal), which increases the risk of metabolic diseases in women. The study indicates the need for education and implementation of disease prevention programs regarding abdominal fat distribution and overweight among young women.

\section{Key words: Distribution of fat - Physical activity - Young women - Somatic profile}

\section{Introduction}

The total amount of adipose tissue and its distribution have a significant impact on the risk of occurrence of cardiovascular diseases. In women with a comparable body mass index (BMI), the waist to hip ratio (WHR) may vary. An increasing amount of visceral fat and thus the occurrence of central obesity increases the risk of metabolic syndrome [9].

It is believed that having waist circumference more than $102 \mathrm{~cm}$ in men and more than $88 \mathrm{~cm}$ in women shows central fat distribution or apple shape obesity and considers as a risk factor for cardiovascular diseases, high blood pressure and diabetes. The waist circumference plays a key role in the development of metabolic disorders, which are found in one third of the obese [23, 29].

As shown in the Inter Heart study, abdominal obesity is the second most common cardiometabolic risk factor for myocardial infarction, in addition to hypertension, hypercholesterolemia or smoking [21]. According to scientific reports, the amount of visceral fat (especially after menopause) and subcutaneous fat tissue increases in women with age and hormonal changes. The area of fat mass in the ventricle is also growing, especially in mature women [25].

The amount of adipose tissue and the site of its accumulation in the body significantly affect the risk of developing metabolic, cardiovascular, and cancer diseases. Both excess body fat and its deficiency have serious health consequences in women, especially during the working age $[14,20]$.

Obesity is a risk factor for infertility and pregnancy as well as perinatal complications [10]. Excessive body mass and body fat also increase the risk of fetal metabolic diseases and affect menstrual disorders in young women [7].

Among women with an elevated waist-hip ratio (WHR), as indicated by the studies [1, 19], mortality from 
breast cancer is higher compared with women with values not exceeding 0.8 .

In addition to the factors directly linked to the structure and composition of the body, lifestyle-related factors contribute to increased risk of the development of many diseases at an early age, particularly abnormal nutrition, stress and lack of physical activity, but also, to some extent, genetic factors [4].

Studies show that the risk of obesity and related diseases such as diabetes, cardiovascular disease or some cancers increases among inactive people [3, 6, 29].

In recent years the world has seen a decline in the amount of physical activity being undertaken in each age group. This situation is conducive to the development of many metabolic diseases from an early age due to the accumulation of excess adipose tissue, particularly in the visceral area. This problem was noted by the World Health Organization [26], which issued recommendations on the recommended amount of physical activity for people of all ages. Adults aged 18-64 should do at least 150 minutes of moderate-intensity aerobic physical activity throughout the week or at least 75 minutes of vigorous-intensity aerobic physical activity throughout the week or an equivalent combination of moderate- and vigorous-intensity activity [26].

Such an amount of physical activity ensures good physical fitness and prevents excessive body weight and reduces the chance of fat accumulation over the years.

Physical activity is defined as any bodily movement produced by skeletal muscles that requires energy expenditure. Physical inactivity (lack of physical activity) has been identified as the leading risk factor for global mortality ( $6 \%$ of deaths globally). Moreover, physical inactivity is estimated to be the main cause of approximately 21$25 \%$ of breast and colon cancers, $27 \%$ of cases of diabetes and approximately $30 \%$ of the ischemic heart disease burden [26].

We are currently observing an increasing number of people with overweight and abdominal obesity. Physical activity is still too low. These unfavorable factors are dependent on each other.

The aim of the study was to evaluate the total fat and fat distribution in young, active and physically inactive women.

\section{Material and methods}

The study group consisted of a total of 300 women aged 20 to $25(21.6 \pm 1.4$ years $)$, female students from Warsaw. The subjects were divided into two groups depending on the physical activity they undertook. The first group consisted of 120 students with sufficient physical activity (mainly Physical Education students of the Physical Education Academy in Warsaw), whilst the other group consisted of 180 students (mainly Dietetics and Physiotherapy) with insufficient physical activity.

The division into two groups with differentiated physical activity was based on the classification proposed by Biernat et al. [2] taking into account the weekly physical activity. The evaluation of the weekly physical activity was carried out using the direct interview method. The interview was conducted by a trained interviewer with each examined woman. The MET (metabolic equivalent task) values obtained during intense, moderate and walking activities were summarized. Activities undertaken during the whole week were considered. Classification of physical activity was done according to the criteria: insufficient - when total energy expenditure did not reach $600 \mathrm{MET} \mathrm{min} /$ week; enough - when total energy expenditure is between 600 and $1500 \mathrm{MET} /$ week, assuming that expenditure is the result of 3 or more days of intensive physical activity for a minimum of 20 minutes per day, 5 or more days of moderate physical activity or walking - for at least 30 minutes, a combination of intense or moderate physical activity giving more than 600 MET min/week [2].

The study was conducted from September 2016 to February 2017. A random sample was selected from the student record list. The criterion for inclusion in the study was the written consent of the students to participate in the study and to carry out somatic measurements.

The primary method of the study was somatometry. Basic anthropometric measurements were made according to the methodology of biological studies: height and weight, waist measurement and hips. The height of the body was measured with an anthropometer with an accuracy of $1 \mathrm{~mm}$. Body weight was measured using medical scales, in the morning on an empty stomach, without clothing. The result was read with an accuracy of $0.1 \mathrm{~kg}$. Waist and hip measurements were made with a metric tape accurate to $0.5 \mathrm{~cm}$.

The body mass index (BMI) for adults with the WHO classification [28] was used to assess relative body weights. Based on anthropometric measurements, waist and hip measurements, the WHR (waist to hip ratio) fat distribution index was calculated using the WHO (30) criterion for women where the android (central fat distribution or apple shape) type of fat was adopted for $\geq 0.8$, and gynoid (buttock) for $<0.8$ (17). The overall body fat content was assessed by bioelectric impedance (BIA) using a Jawon $\mathrm{x}$-scan analyzer. The classification of general fatty tissue was made according to Gallagher et al. [10] for women aged 20-39, with low content of fat $<21.0 \%$, standard from 21.0 to $32.9 \%$, high from 33.0 to $38.9 \%$, and very high above $39 \%$.

The data analysis was performed using selected statistical methods in STATISTICA software (v. 12, Stat. Soft. USA). Statistically significant differences in pairs between 
two groups were assessed by t-test for independent groups (level of significance $\mathrm{p}<0.001$ ). Statistically significant differences in pairs between two groups, the percentage of the sample or sub-sample were assessed by the $\chi^{2}$ test (level of significance $\mathrm{p}<0.001$ ).

\section{Results}

The results show that physically active students have significantly lower body weight, waist and hip size, lower body fat content and lower BMI and WHR values compared with their physically inactive peers $(\mathrm{p}<0.001)$. The intensity of activity determined by the metabolic equivalent
(MET) effort was significantly different between the two groups of women. Underweight was more frequent among physically active subjects compared to inactive students, whilst excessive body weight was predominantly in inactive students. Evaluation of adipose tissue distribution showed that physically active women were significantly more frequently $(\mathrm{p}<0.001)$ characterized by a gynoidal type of adipose tissue compared to physically inactive, predominantly android-abdominal adipose tissue distribution. More than half of all respondents reported low body fat. It was also found that the category of low adipose tissue content in the body was significantly more frequent among physically active subjects compared with non-active subjects $(\mathrm{p}<0.001)$ (Table 1$)$.

Table 1. Sample characteristics by active and inactive of female students

\begin{tabular}{|c|c|c|c|c|}
\hline \multirow{2}{*}{ Category } & \multirow{2}{*}{ Total } & \multicolumn{2}{|c|}{ Group } & \multirow{4}{*}{$\mathrm{p}$} \\
\hline & & Active & Inactive & \\
\hline Number of subject & 300 & 120 & 180 & \\
\hline Percentage of total sample & 100 & 40 & 60 & \\
\hline Body weight $[\mathrm{kg}]^{*}$ & $\begin{array}{c}60.3 \pm 8.5 \\
(43.8-81.2) \\
\end{array}$ & $\begin{array}{c}54.3 \pm 5.5 \\
(43.8-70.2)\end{array}$ & $\begin{array}{l}64.3 \pm 7.75 \\
(45.8-81.2)\end{array}$ & $\mathrm{p}<0.001$ \\
\hline Body height $[\mathrm{cm}]$ & $\begin{array}{c}166.9 \pm 4.8 \\
(155-182) \\
\end{array}$ & $\begin{array}{c}167.1 \pm 5.1 \\
(156-181) \\
\end{array}$ & $\begin{array}{c}166.9 \pm 4.75 \\
(155-182) \\
\end{array}$ & ns \\
\hline BMI $\left[\mathrm{kg} / \mathrm{m}^{2}\right]^{*}$ & $\begin{array}{c}21.6 \pm 3.1 \\
(16.7-29.8) \\
\end{array}$ & $\begin{array}{c}19.4 \pm 1.7 \\
(16.7-24.5) \\
\end{array}$ & $\begin{array}{c}23.1 \pm 2.9 \\
(16.8-29.8)\end{array}$ & $\mathrm{p}<0.001$ \\
\hline $\begin{array}{l}\text { Underweight }[\%]^{\#} \\
\text { Normal weight [\%] } \\
\text { Overweight [\%] } \\
\text { Obesity [\%] }\end{array}$ & $\begin{array}{c}15.7 \\
69.0 \\
15.3 \\
0\end{array}$ & $\begin{array}{c}30.8 \\
69.2 \\
0 \\
0\end{array}$ & $\begin{array}{c}5.6 \\
68.8 \\
25.6 \\
0\end{array}$ & $\mathrm{p}<0.001$ \\
\hline Percentage of fat* & $\begin{array}{c}20.9 \pm 4.0 \\
(11.3-35.3) \\
\end{array}$ & $\begin{array}{c}18.7 \pm 1.9 \\
(16.7-24.5) \\
\end{array}$ & $\begin{array}{c}22.3 \pm 4.4 \\
(11.3-35.3) \\
\end{array}$ & $\mathrm{p}<0.001$ \\
\hline $\begin{array}{l}\text { Category of fat } \\
\text { Low }[\%]^{\#} \\
\text { Norm }[\%]^{\#} \\
\text { High fat content }[\%]\end{array}$ & $\begin{array}{c}60 \\
39 \\
1 \\
\end{array}$ & $\begin{array}{c}86.7 \\
13.3 \\
0\end{array}$ & $\begin{array}{c}42.2 \\
56.1 \\
1.7 \\
\end{array}$ & $\mathrm{p}<0.001$ \\
\hline Waistcircumference $[\mathrm{cm}]^{*}$ & $\begin{array}{l}73.5 \pm 7.0 \\
(59-102) \\
\end{array}$ & $\begin{array}{c}69.55 \pm 6.4 \\
(59-91) \\
\end{array}$ & $\begin{array}{c}76.2 \pm 6.1 \\
(60-102) \\
\end{array}$ & $\mathrm{p}<0.001$ \\
\hline Hip circumference $[\mathrm{cm}]^{*}$ & $\begin{array}{c}89.0 \pm 5.3 \\
(70-102)\end{array}$ & $\begin{array}{c}87.6 \pm 5.6 \\
(70-97)\end{array}$ & $\begin{array}{c}89.9 \pm 4.95 \\
(79-102)\end{array}$ & $\mathrm{p}<0.001$ \\
\hline WHR $[\mathrm{cm} / \mathrm{cm}]^{*}$ & $\begin{array}{l}0.83 \pm 0.07 \\
(0.64-1.07) \\
\end{array}$ & $\begin{array}{l}0.79 \pm 0,06 \\
(0.64-0.95)\end{array}$ & $\begin{array}{l}0.85 \pm 0.06 \\
(0.68-1.07)\end{array}$ & $\mathrm{p}<0.001$ \\
\hline $\begin{array}{l}\text { Type of fat distribution } \\
\text { Androidal }[\%]^{\#} \\
\text { Gynoidal }[\%]^{\#}\end{array}$ & $\begin{array}{l}65.3 \\
34.7 \\
\end{array}$ & $\begin{array}{l}46.7 \\
53.3 \\
\end{array}$ & $\begin{array}{l}77.8 \\
22.2 \\
\end{array}$ & $\mathrm{p}<0.001$ \\
\hline MET* $^{*}$ & $\begin{array}{c}941.5 \pm 932.1 \\
(76-3705)\end{array}$ & $\begin{array}{c}1852.0 \pm 862.8 \\
(756-3705)\end{array}$ & $\begin{array}{c}334.6 \pm 173.4 \\
(76-600)\end{array}$ & $\mathrm{p}<0.001$ \\
\hline
\end{tabular}

* - expressed as mean and standard deviation (min-max), statistically significant differences in pairs between two groups (levels of significance were assessed by T test), $\mathrm{p}<0.001$; \# - statistically significant differences in pairs between two groups, percentage of the sample or sub-sample (levels of significance were assessed by $\chi^{2}$ test), $\mathrm{p}<0.001$. 
Among physically inactive students with excessive body weight (overweight), average overall adiposity exceeded $25 \%$. Among women with normal BMI, body fat content was reduced by $2 \%$ in physically active versus inactive subjects. The lowest overall fat level was reported in underweight physically inactive women (below 14\% fat) (Fig. 1).

Evaluation of WHR and BMI showed that physically inactive students were characterized by the unhealthy type of adipose tissue distribution. Among women with normal BMI, android type was present significantly more frequently $(\mathrm{p}<0.001)$ in physically inactive ones. Underweight was predominant among active students, with both the android type and the gynoidal type (Fig. 2).

On the basis of the research results, somatic profiles were created: health-promoting and two anti-health ones. It was found that the health-promoting profile characterized by normal BMI, gynoidal type distribution of adipose tissue and normal or slightly lower body fat was significantly more common in physically active versus inactive subjects. The first anti-health profile was reported in $13 \%$ of all students, especially among active women. In contrast, the second anti-health profile was reported only in physically inactive women (Fig. 3).

\section{Discussion}

Lifestyle is considered to be an integral part of the socio-cultural sphere, which significantly affects an individual's health. Researchers believe that lifestyle is a determinant responsible for the widespread epidemic of overweight and health problems proceeding from it $[12,17]$.

The POL HEALTH National Program for the Prevention of Illness and Diseases shows significant differences in the health of society, depending on the degree of body fat in relation to the lifestyle adopted by the individual. In reports devoted to lifestyle in the context of their

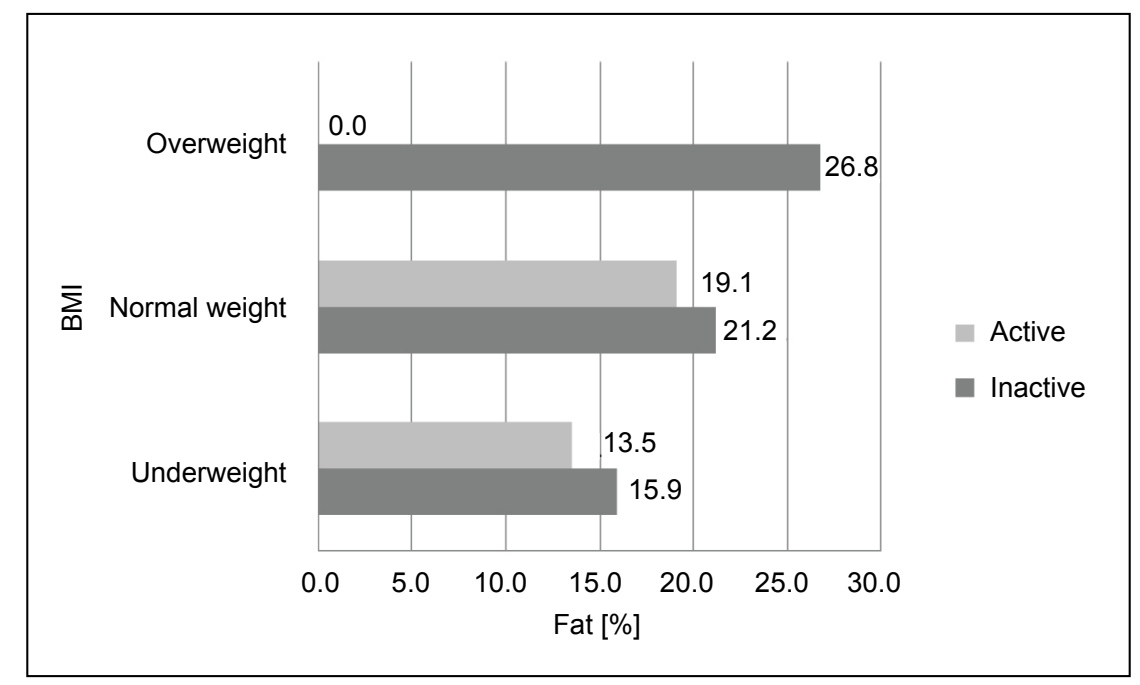

Fig. 1. Analysis of total body fat in relation to BMI and level of physical activity

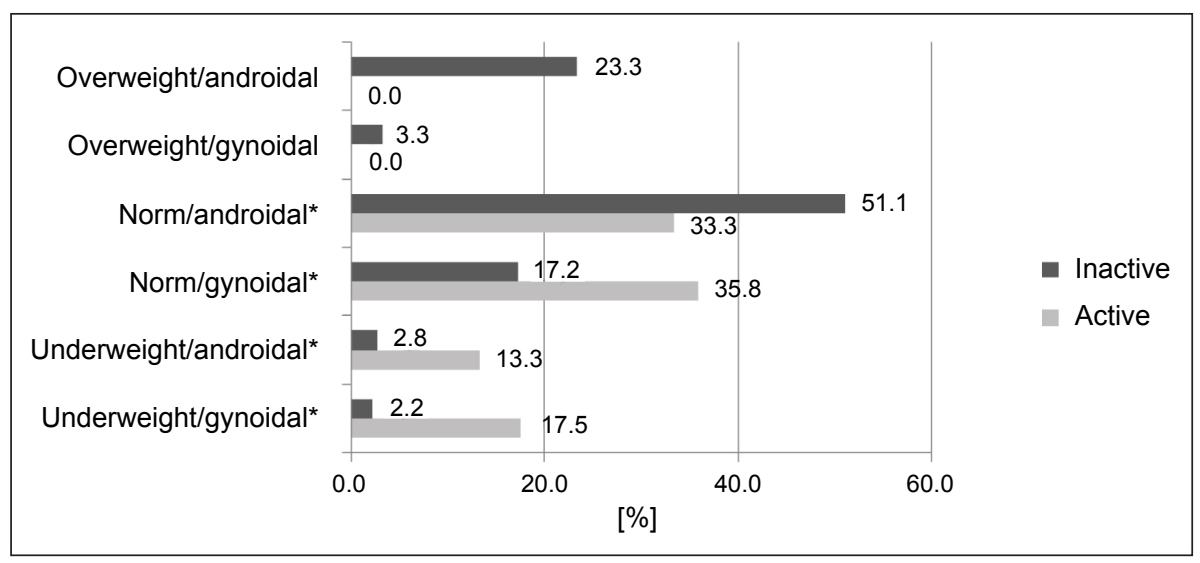

Fig. 2. Analysis of fat type distribution in relation to BMI and level of physical activity $(*-p<0.001)$ 


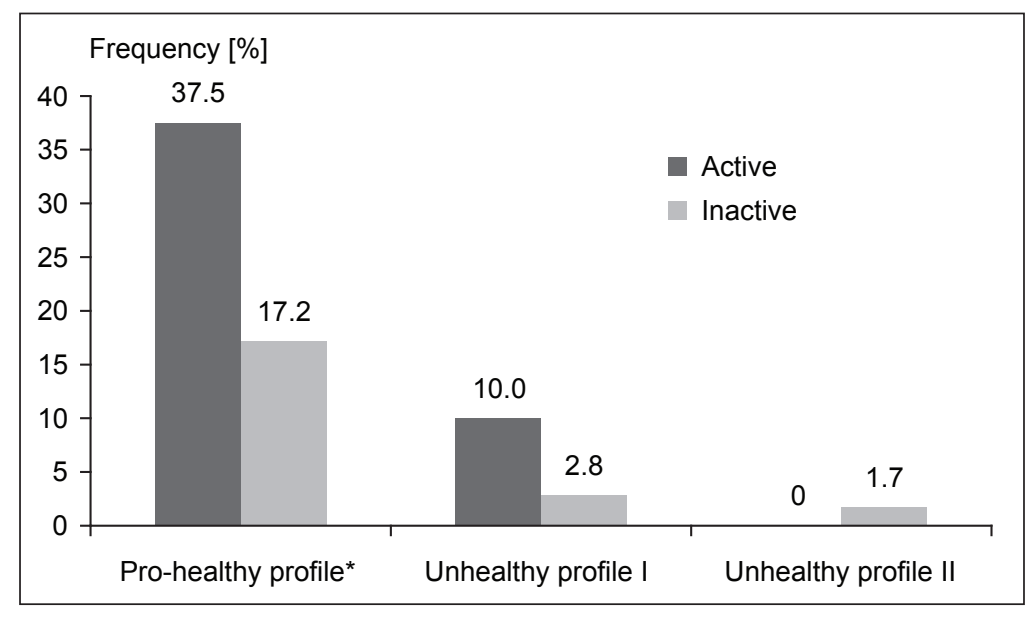

Fig. 3. Occurrence of pro-health somatic profile and anti-health profiles in active and inactive female students $(*-p<0.001)$. Pro-healthy profile - BMI, gynoid type of adipose tissue distribution and normal or slightly underweight fat $\%$; Unhealthy profile I - underweight, type of android fat distribution and underweight fat \%; Unhealthy profile II - overweight, type of android fat distribution and high fat content $\%$

association with individual health, great attention is devoted to a number of abnormalities such as eating disorders or low levels of physical activity $[21,23]$.

In common medical practice, body mass index (BMI) is used to determine the nutritional status of adults. It is considered one of the strongest predictors of a cardiac event. It has been shown that an increase in BMI of $1 \mathrm{~kg} / \mathrm{m}^{2}$ is associated with a $4 \%$ increase in the incidence of coronary artery disease [5].

The results of the present research revealed that among the surveyed students in Warsaw the majority (about 70\%) had a normal body mass. There was also underweight (about 15\%) and the same percentage with overweight. Physical activity is a factor determining the occurrence of certain extreme types of BMI. Active students were significantly more likely to have short-term weight gain, and overweight was reported only in inactive women.

Kromhout et al. [15] demonstrated that physical activity affects the BMI. The lower the motor activity, the higher the BMI.

The same conclusion was drawn by Jebb et al. [13], who found that low levels of physical activity correlated significantly with higher BMI values and led to faster accumulation of excess body mass and fat gain in a population of different age and sex.

Ross et al. [20] demonstrated that increased physical activity affects weight loss and reduction of both body fat, both as a whole and subcutaneous.

Other positions on this issue were presented by Stachon et al. [22]. The results of their research show that Physical Education students (physically active) did not significantly differ in their BMI values from their Physiotherapy peers. However, it is worth emphasizing that, in comparison to students from other degree courses and other universities, both Physical Education and Physiotherapy in the study program have practical hands-on activities related to various forms of physical activity.

The results of our own research show that the level of physical activity of young women significantly affects the amount of body fat and the distribution of this tissue. Physically active students were characterized by a lower level of fat amount assessed by means of biochemical impedance (BIA) $(\mathrm{p}<0.001)$ and a gynoidal type of adipose tissue distribution considered healthier than an android type.

The results are confirmed by Stachon et al. [22], who found that total body fat in young physically active women was over $2 \%$ lower than those with low motor activity. These were statistically significant differences. In these studies, it was also found that physically active women had lower values of all skin-fat folds examined. The difference in thickness of skin-fat folds between the least and the most physically active was $1-2 \mathrm{~cm}$.

Research by other authors $[11,18]$ shows a strong dependence of the increase in fatness along with a decrease in the level of physical activity. The present studies showed that androidal type of fat distribution was much more common in physically inactive subjects. The type of adipose tissue distribution analyzed with the nutritional status of the subjects studied and their level of physical activity showed that physically active students significantly more frequently had BMI in the normal range and gynoidal type of adipose tissue distribution, and inactive students more frequently had normal BMI values and android type fat distribution. Lack of physical activity and the associated excess fatness results from a positive energy balance. Excessive fatty tissue, especially visceral, causes damage of internal organs. This condition can significantly aggravate the increased risk of diseases associated with improper fat 
accumulation, especially cardiovascular diseases, atherosclerosis, cerebral stroke [21, 23].

Slightly different conclusions have been drawn from the studies of Stachon et al. [22] Among women who are physically active, there is a tendency for aneroid obesity and much less accumulation of fat on the hips and thighs compared with their less physically active peers. In the studies of active female underweight students, there was found android adipose tissue distribution, yet the overall content of the body fat was low.

Zuzda et al. [30] pointed that among the examined students in Bialystok the average value of the WHR was 0.86. In our own study, compared with the study of the students from Bialystok, the WHR was lower in all the examined women (0.83). Taking into account the physical activity of the subjects, it was found that the average value of WHR in physically active females was lower in comparison to the physically inactive students $(0.79$ vs. 0.86$)$. These were statistically significant differences.

From our own research and review of available literature, it might be concluded that the assessment of relative $\mathrm{BMI}$ in relation to general fat and fatty tissue distribution should be an important diagnostic element and early predictor of many diseases in women.

Study limitation. The authors of the paper are aware of some limitations of the study and the need to continue and expand their research. A great complement to the present results would be to make measurements among a larger population of young women from different backgrounds, and to include nutritional analysis, in particular the quantity and quality of fat consumed.

\section{Conclusions}

1. Physical inactivity was associated with larger waist and hip circumference, greater BMI and unfavorable adipose tissue distribution. Lack of physical activity increases the risk of metabolic diseases in women.

2. The unfavorable somatic profile occurred only among inactive students.

3. The research indicates the need for education and implementation of disease prevention programs related to abdominal fat distribution and overweight among young women, especially in non-physical education.

\section{Conflict of interest: Authors state no conflict of interest.}

\section{References}

1. Adebam C.A., Ogundiran T.O., Adenipekun A.A, Oyesegun R.A., Campbell O.B., Akang E.E., Rotimi Ch.N., Olopade O.I. (2003) Waist-hip ratio and breast cancer risk in urbanized Nigerian women. Breast. Cancer. Res., 5(2): 18-24.

2. Biernat E., Stupnicki R., Gajewski A. (2007) International Physical Activity Questionnaire (IPAQ) - Polish version. Phys. Edu. Sport, 51(1): 47.

3. Cameron A., Welborn T., Zimmet P., Dustan D., Owen N., Salmon J., Dalton M., Jolley D., Shaw J.E. (2003) Overweight and obesity in Australia. The 1990-2000 Australian diabetes, obesity and lifestyle study. Med. J. Aust., 178(9): 427-432.

4. Cardon L.R., Carmelli D., Fabsitz R.R., Reed T. (1994) Genetic and environmental correlations between obesity and body fat distribution in adult male twins. Hum. Biol., 66(3): 465-479.

5. Carey V.J. Walters E.E., Colditz G.A., Solomon C.G., Willett W.C., Rosner B.A., Speizer F.E., Manson J.E. (1997) Body fat distribution and risk of non-insulin-dependent diabetes mellitus in women. Am. J. Epidemiol., 145(7): 614-619.

6. Cheng S-J., Yu H.-K., Chen Y.-C., Chen C.-Y., Lien W.-C., Yang P.-Y., Hu G.-C. (2013) Physical Activity and Risk of Cardiovascular Disease Among Older Adults. Int. J. Gerentol., 7: 133-136.

7. Fontana R., Torre S.D. (2016) The Deep Correlation between Energy Metabolism and Reproduction: A View on the Effects of Nutrition for Women Fertility. Nutrients., 8(2): 87.

8. Gallagher D., Heymsfield S.B., Heo M., Jobb S.A., Murgatroyd P.R., Sakamoto Y. (2000) An approach for developing guidelines based on body mass index. Am. J. Clin. Nutr., 72: 694-701.

9. Garaulet M., Perez-Liamas F., Baraza J.C., Garcia-Prieto M.D., Fardy P.S., Tébar F.J., Zamora S. (2002) Body fat distribution in pre-and postmenopausal women: metabolic and anthropometric variables. J. Nutr. Health Aging., 6: 123-126.

10. Hajduk M. (2012) The effect of body weight on fertility in women. Endokr. Obese. Zab. Me. Mat., 8(3): 93-97.

11. Janz K.F., Kwon S., Letuchy E.M. Eichenberger Gilmore J.M., Burns T.L., Torner J.C. Willing M.C., Levy S.M. (2009) Sustained Effect of Early Physical Activity on Fat Mass in Older Children. Am. J. Prev. Med., 37(1): 35-40. DOI: 10.1016/j.amepre.2009.03.012.

12. Jarosz M., Rychlik E. (2010) Obesity epidemic - what future awaits us? Gasteoenterol. Pol., 17(1): 47-52.

13. Jebb S., Moore M.S. (1999) Contribution of a sedentary lifestyle and inactivity to the ethics of overweight and obesity: current evidence and research issues. Med. Science. Sports. Exerc., 31(11): 534-541.

14. Kiechengast S., Huber J. (2001) Body composition and body fat distribution in lean women with polycystic ovary syndrome. Hum. Reprod., 16(6): 1255-1260.

15. Kromhout D., Bloemberg B., Seidell J.C., Nissinen A., Menotti A. (2001) Physical activity and dietary fiber 
determination of body fat levels: the seven countries study. Int. J. Obesity., 25(3): 301-306.

16. Lee D.C., Park I., Jun T.W., South B.H., Cho S.I., Blair S.N. (2012) Physical Activity and Body Mass Index and Their Associations with Development of Type 2 Diabetes in Korean. Men. Am. J. Epidemiol., 176(1): 43-51.

17. Mahoney D. (2014) Lifestyle modification intervention among infertile overweight and obese women with polycystic ovary syndrome. J. Am. Assoc. Nurse. Pract., 26(6): 301-308.

18. Moghadam M., Hajikazemi E., Roozber M., Hoshyar A., Fatemeh Hosseini A. (2011) Relationship between Physical Activity and Triceps. Skin Fold Thickness in adolescent girl students. Iran. J. Nurs., 24(69): 62-68.

19. Moorman P.G., Jones B.A., Millikan R.C. (2001) Race, anthropometric factors, and stage At diagnosis of breast cancer. Am. J. Epidemiol., 153(3): 284-291.

20. Ross R., Janssen I. (2001) Physical activity, total and regional obesity: dose - response considerations. Med. Sci. Sports. Exerc., 33(6): 521-527.

21. Rynkiewicz A. (2008) Prevention of cardiovascular disease among women in Europe. Menopause Rev., 3: 107-113.

22. Stachoń A., Pietraszewska J., Burdukiewicz A., Andrzejewska J. (2013) The influence of physical activity on the level of fatness of young women. General Med. Health Sci., 19(2): 188-192.

23. Suchecka-Rachoń K., Rachoń D. (2007) Obesity - basic element of the metabolic syndrome. Cardiology Day, 3(2): 120-124.

24. Tao M.H., Shu X.O., Ruan Z.X., Gao Y.T., Zheng W. (2006) Association of overweight with breast cancer survival. Am. J. Epidem., 163: 101-107.
25. Toth M.J., Tchernof A., Sites C.K., Poehlman E.T. (2000) Menopausal changes in body fat distribution. Ann. NY. Acad. Sci., 904: 502-506.

26. World Health Organizations. (2004) Global Strategy on Diet, Physical Activity \& Health. Recommended levels of physical activity for adults aged 18-64 years. Geneva.

27. World Health Organizations. (2008) Waist Circumference and Waist-Hip Ratio Report of WHO Expert Consultation GENEVA, 8-11 DECEMBER 2008.

28. World Health Organization. (2011) Global Database on Body Mass Index. An interactive surveillance tool for monitoring nutrition transition 2011.

29. Zhang C., Rexrode K., van Dam R., Li T., Hu F.B. (2008) Abdominal obesity and the risk of all-cause, cardiovascular, and cancer mortality: sixteen years of follow-up in US women. Circulation, 26: 968-976.

30. Zuzda J., Latosiewicz R., Półjanowicz W. (2010) Obesity research among students and students of Bialystok University of Technology and Bialystok Higher School of Economics. Economy and Management, 1: 74-80.

\section{Received 20.10.2017 \\ Accepted 02.02.2018}

\section{(C) University of Physical Education, Warsaw, Poland}

\section{Acknowledgments}

The study was conducted and financed within the DM-48 project included in the statutory activities of the Józef Piłsudski University of Physical Education in Warsaw. 